\title{
FOUCAULT E A ANÁLISE DO DISCURSO EM EDUCAÇÃO
}

\author{
ROSA MARIA BUENO FISCHER \\ Faculdade de Educação e Programa de Pós-Graduação em Educação \\ da Universidade Federal do Rio Grande do Sul \\ rosamar@plug-in.com.br
}

\begin{abstract}
RESUMO
Neste artigo são apresentados e discutidos alguns importantes conceitos da teoria do discurso de Michel Foucault, especialmente os conceitos de enunciado, prática discursiva, sujeito e heterogeneidade do discurso. A partir do referencial foucaultiano, explicita-se a íntima relação entre discurso e poder, bem como as várias e complexas formas de investigar as "coisas ditas". Oobjetivo é mostrar a produtiva contribuição desse referencial teórico e metodológico para as pesquisas em educação, nas quais que se pretende "analisar discursos".

FOUCAULT,M. - PESQUISAEDUCACIONAL -DISCURSO
\end{abstract}

\begin{abstract}
FOUCAULT AND ANALYSIS OF DISCOURSE ON EDUCATIONAL RESEARCHES. In this paper, I present and discuss some important concepts from Michel Foucault's theory of discourse, specially the concepts of statement, discoursive practice, subject and discoursive heterogeneity. From this theoretical reference, I explain the intimate relation between discourse and power, as well as several and complex forms to investigate "expressed things". The aim is to indicate productive contribution of this theoretical and methodological reference to educacional researches which intend to "analyze discourses".
\end{abstract}

Este texto, com as devidas adaptações, contém parte da discussão teórica elaborada para tese de doutorado (Fischer, 1996). 
O objetivo deste artigo é oferecer elementos para uma discussão teórica e metodológica sobre o conceito de discurso em Michel Foucault e a respectiva contribuição para as investigações no campo educacional. Tal empreitada se justifica, à medida que proliferam nesta área pesquisas que se propõem a "analisar discursos" - de professores e professoras, de alunos de diferentes níveis, de instituições ligadas à educação, de textos oficiais sobre políticas educacionais, entre outros. Apresento aqui os principais conceitos relacionados à teoria foucaultiana do discurso - enunciado, prática discursiva, sujeito do discurso, heterogeneidade discursiva -, tecendo comentários sobre as ricas possibilidades que essa proposta oferece em termos teóricos e metodológicos. Para melhor entendimento da teoria, utilizo ora exemplos genéricos do campo da educação, ora exemplos específicos de uma pesquisa' sobre as relações entre mídia e adolescência.

\section{A CONSTRUÇÃO DISCURSIVA DO SOCIAL}

Para analisar os discursos, segundo a perspectiva de Foucault, precisamos antes de tudo recusar as explicações unívocas, as fáceis interpretações e igualmente a busca insistente do sentido último ou do sentido oculto das coisas - práticas bastante comuns quando se fala em fazer o estudo de um "discurso". Para Michel Foucault, é preciso ficar (ou tentar ficar) simplesmente no nível de existência das palavras, das coisas ditas. Isso significa que é preciso trabalhar arduamente com o próprio discurso, deixando-o aparecer na complexidade que lhe é peculiar. E a primeira tarefa para chegar a isso é tentar desprender-se de um longo e eficaz aprendizado que ainda nos faz olhar os discursos apenas como um conjunto de signos, como significantes que se referem a determinados conteúdos, carregando tal ou qual significado, quase sempre oculto, dissimulado, distorcido, intencionalmente deturpado, cheio de "reais" intenções, conteúdos e representações, escondidos nos e pelos textos, não imediatamente visíveis. É como se no interior de cada discurso, ou num tempo anterior a ele, se pudesse encontrar, intocada, a verdade, desperta então pelo estudioso.

Para Foucault, nada há por trás das cortinas, nem sob o chão que pisamos. Há enunciados e relações, que o próprio discurso põe em funcionamento. Analisar o discurso seria dar conta exatamente disso: de relações históricas, de práticas

I. Refiro-me à tese de doutorado (Fischer, 1996), na qual analisei produtos da mídia como a revista Capricho, a série de TV Confissões de Adolescente, o caderno Folhateen, da Folha de S. Paulo, e o Programa Livre, do SBT. 
muito concretas, que estão "vivas" nos discursos. Por exemplo: analisar textos oficiais sobre educação infantil, nessa perspectiva, significará antes de tudo tentar escapar da fácil interpretação daquilo que estaria "por trás" dos documentos, procurando explorar ao máximo os materiais, na medida em que eles são uma produção histórica, política; na medida em que as palavras são também construções; na medida em que a linguagem também é constitutiva de práticas.

Então declara-se nesse caso a completa autonomia do discurso, o reino absoluto e independente das palavras? O discurso organizaria a si mesmo, inclusive as práticas sociais? Talvez as obras foucaultianas da década de 60 - As Palavras e as coisas e A Arqueologia do saber -, como registra David Couzens Hoy (1988), sugerissem essa concepção idealista e estruturalista da linguagem, o que inclusive foi admitido por Foucault. Porém, a idéia de categorias universalmente constitutivas, próprias do estruturalismo e do idealismo filosófico, jamais se ajustou ao projeto maior do filósofo. Segundo Dreyfus e Rabinow (1984), ele desejava demonstrar exatamente o contrário, ou seja, a inexistência de estruturas permanentes, responsáveis pela constituição da realidade. A conceituação de discurso como prática social - já exposta em A Arqueologia, mas que se torna bem clara em Vigiar e punir e na célebre aula $A$ Ordem do discurso - sublinha a idéia de que o discurso sempre se produziria em razão de relações de poder. E, mais tarde, nos três volumes de sua História da sexualidade, o pensador mostra explicitamente que há duplo e mútuo condicionamento entre as práticas discursivas e as práticas não discursivas, embora permaneça a idéia de que o discurso seria constitutivo da realidade e produziria, como o poder, inúmeros saberes. Na verdade, ele falou disso desde o início de suas investigações; em A Arqueologia do sabero mesmo assunto aparece sob a forma de reflexão sobre o trabalho realizado e sobre projetos futuros:

...gostaria de mostrar que o discurso não é uma estreita superfície de contato, ou de confronto, entre uma realidade e uma língua, o intrincamento entre um léxico e uma experiência; gostaria de mostrar, por meio de exemplos precisos, que, analisando os próprios discursos, vemos se desfazerem os laços aparentemente tão fortes entre as palavras e as coisas, e destacar-se um conjunto de regras, próprias da prática discursiva. (...) não mais tratar os discursos como conjunto de signos (elementos significantes que remetem a conteúdos ou a representações), mas como práticas que formam sistematicamente os objetos de que falam. Certamente os discursos são feitos de signos; mas o que fazem é mais que utilizar esses signos para designar coisas. É esse mais que os torna irredutíveis à língua e ao ato da fala. É esse "mais" que é preciso fazer aparecer e que é preciso descrever. (Foucault, 1986, p.56) 
Na verdade, tudo é prática em Foucault. E tudo está imerso em relações de poder e saber, que se implicam mutuamente, ou seja, enunciados e visibilidades, textos e instituições, falar e ver constituem práticas sociais por definição permanentemente presas, amarradas às relações de poder, que as supõem e as atualizam. Nesse sentido, o discurso ultrapassa a simples referência a "coisas", existe para além da mera utilização de letras, palavras e frases, não pode ser entendido como um fenômeno de mera "expressão" de algo: apresenta regularidades intrínsecas a si mesmo, através das quais é possível definir uma rede conceitual que lhe é própria. É a esse "mais" que o autor se refere, sugerindo que seja descrito e apanhado a partir do próprio discurso, até porque as regras de formação dos conceitos, segundo Foucault, não residem na mentalidade nem na consciência dos indivíduos; pelo contrário, elas estão no próprio discurso e se impõem a todos aqueles que falam ou tentam falar dentro de um determinado campo discursivo (Foucault, 1986, p.70).

O teórico Ernesto Laclau explicita muito bem esse conceito de discurso, pelo qual os atos de linguagem constituem uma trama que ultrapassa o meramente lingüístico. Para ele, o discurso seria uma instância limítrofe com o social. "Porque cada ato social tem um significado, e é constituído na forma de seqüências discursivas que articulam elementos lingüísticos e extralingüísticos" (Laclau, I 99 I , p. I 37). Segue daí uma nova conceituação de objetividade (as práticas sociais se constituiriam discursivamente), bem como um modo novo de conceber as identidades sociais ou subjetivas, mergulhadas num relativismo bastante radical, dado por esse jogo permanente dos sentidos. Para Laclau, a sociedade seria assim entendida "como um vasto tecido argumentativo no qual a humanidade constrói sua própria realidade" (idem, p. |46).

Afirmar que os discursos formam os objetos de que tratam ou, como Laclau, que não se pode falar em "realidade objetiva" sem entender que esta se constrói por dentro de uma trama discursiva, pode à primeira vista significar uma opção idealista, conforme mencionamos anteriormente. No entanto, além de o conjunto da obra de Foucault demonstrar o contrário dessa opção, pode-se dizer da "positividade" desse suposto radicalismo que o leva a quase afirmar a completa autonomia dos discursos: sua insistência em negar teorias totalizantes de explicação da realidade social, bem como de negar uma visão de "progresso" científico ou progresso da razão, de superioridade do presente em relação ao passado, faz com que Foucault "revolucione a história", como diz Paul Veyne. Ele se define como um historiador do presente, por inquietar-se profundamente com o que 
nos sucede hoje, e se entrega a perscrutar a genealogia dos grandes temas constituintes do homem ocidental, através da descrição minuciosa de práticas sociais em sua descontinuidade histórica - mergulhadas em relações de poder, produzidas discursivamente e ao mesmo tempo produtoras de discursos e de saberes. Basicamente, tais temas dizem respeito à fixação em saber a verdade do sujeito, em constituir os sujeitos como o lugar da verdade, em construir para todos e cada um de nós discursos "verdadeiros".

\section{O ENUNCIADO: UMA FUNÇÃO QUE “ATRAVESSA” A LINGUAGEM}

"Chamaremos de discurso um conjunto de enunciados que se apóiem na mesma formação discursiva" (Foucault, 1986, p.135). Essa é uma das inúmeras definições de discurso, presentes na obra A Arqueologia do saber e, como todas as demais, não pode ser compreendida isoladamente. Tudo na obra do filósofo tem conexões que precisam ser explicitadas, caso contrário permanece-se no reino das tautologias e das definições circulares. Tomarei como ponto de partida a explicitação do conceito de enunciado, para chegar posteriormente à discussão dos conceitos de prática discursiva e não-discursiva, formação discursiva e interdiscursividade, já que o conceito de enunciado parece ser o que sintetiza melhor a elaboração do autor sobre uma possível "teoria do discurso".

Em quase todas as formulações sobre discurso, Foucault refere-se ao enunciado. Discurso como "número limitado de enunciados para os quais podemos definir um conjunto de condições de existência", ou como "domínio geral de todos os enunciados", "grupo individualizável de enunciados", "prática regulamentada dando conta de um certo número de enunciados" - são algumas delas ( 1986 , p.90 e 135). A idéia contida nas expressões "condições de existência", "domínio", "grupo individualizável" e "prática regulamentada", usadas nas definições anteriores, é básica para entendermos a definição de enunciado como "função de existência", a qual se exerce sobre unidades como a frase, a proposição ou o ato de linguagem. $\bigcirc$ enunciado em si não constituiria também uma unidade, pois ele se encontra na transversalidade de frases, proposições e atos de linguagem: ele é "sempre um acontecimento, que nem a língua nem o sentido podem esgotar inteiramente" (p. 32); trata-se de "uma função que cruza um domínio de estruturas e de unidades possíveis e que faz com que [estas] apareçam, com conteúdos concretos, no tempo e no espaço" (p. 99).

Não há enunciado que não esteja apoiado em um conjunto de signos, mas o que importa é o fato de essa "função" caracterizar-se por quatro elementos 
básicos: um referente (ou seja, um princípio de diferenciação), um sujeito (no sentido de "posição" a ser ocupada), um campo associado (isto é, coexistir com outros enunciados) e uma materialidade específica - por tratar de coisas efetivamente ditas, escritas, gravadas em algum tipo de material, passíveis de repetição ou reprodução, ativadas através de técnicas, práticas e relações sociais (idem, p. 133 e ss.). Um enunciado como este - "o professor é antes de tudo alguém que se doa, que ama as crianças, que acredita na sua nobre missão de ensinar" - certamente é feito de signos, de palavras. Mas, para Foucault, interessa a sua condição mesma de enunciado, em seus quatro elementos básicos:

I. a referência a algo que identificamos (o referente, no caso, a figura de mestre associada a doação e amor);

2. o fato de ter um sujeito, alguém que pode efetivamente afirmar aquilo (muitos professores e professoras ocupam o lugar de sujeito desse enunciado, e o interessante neste caso seria, por exemplo, descrever quem são os indivíduos que ainda estão nessa condição; mesmo pessoas que não são professores, os "voluntários da educação", também se reconhecem nesse discurso, como tantas vezes vemos em reportagens de jornais e na televisão);

3. o fato de o enunciado não existir isolado, mas sempre em associação e correlação com outros enunciados, do mesmo discurso (no caso, o discurso pedagógico) ou de outros discursos (por exemplo, o discurso religioso, missionário, ou mesmo o discurso sobre a mulher, a maternidade, e assim por diante);

4. finalmente, a materialidade do enunciado, as formas muito concretas com que ele aparece, nas enunciações que aparecem em textos pedagógicos, em falas de professores, nas mais diferentes situações, em diferentes épocas (veja-se como a mídia se apropria desse discurso e o multiplica em inúmeras reportagens sobre pessoas que voluntariamente passam a dedicar-se ao trabalho de "educadores").

Descrever um enunciado, portanto, é dar conta dessas especificidades, é apreendê-lo como acontecimento, como algo que irrompe num certo tempo, num certo lugar. $\bigcirc$ que permitirá situar um emaranhado de enunciados numa certa organização é justamente o fato de eles pertencerem a uma certa formação discursiva. 
Se, ao demarcar uma formação discursiva, revelamos algo dos enunciados, quando descrevemos enunciados procedemos à individualização de uma formação discursiva. Portanto, como escreve Foucault, "a análise do enunciado e da formação discursiva são estabelecidas correlativamente", porque "a lei dos enunciados e o fato de pertencerem à formação discursiva constituem uma única e mesma coisa" (idem, p. I35). Mas o que é uma formação discursiva? Por formação discursiva ou sistema de formação compreende-se:

...um feixe complexo de relações que funcionam como regra: ele prescreve o que deve ser correlacionado em uma prática discursiva, para que esta se refira a tal ou qual objeto, para que empregue tal ou qual enunciação, para que utilize tal conceito, para que organize tal ou qual estratégia. Definir em sua individualidade singular um sistema de formação é, assim, caracterizar um discurso ou um grupo de enunciados pela regularidade de uma prática. (Idem, p.82)

Quais os limites entre uma disciplina e o que Foucault define como formação discursiva? Segundo Maingueneau, as formações discursivas devem ser vistas sempre dentro de um espaço discursivo ou de um campo discursivo, ou seja, elas estão sempre em relação como determinados campos de saber. Assim, quando falamos em discurso publicitário, econômico, político, feminista, psiquiátrico, médico ou pedagógico, estamos afirmando que cada um deles compreende um conjunto de enunciados, apoiados num determinado sistema de formação ou formação discursiva: da economia, da ciência política, da medicina, da pedagogia, da psiquiatria. Isso, porém, não significa definir essas formações como disciplinas ou como sistemas fechados em si mesmos². No caso dos discursos feminista e publicitário, mesmo que não se possa falar na tradição de uma área específica, como ocorre nos outros exemplos, pode-se dizer que seus enunciados têm força de "conjunto" e se situam como novos campos de saber, os quais tangenciam mais de uma formação. A formação discursiva deve ser vista, antes de qualquer coisa, como o "princípio de dispersão e de repartição" dos enunciados (idem, p. 124), segundo o qual se "sabe" o que pode e o que deve ser dito, dentro de determinado campo e de acordo com certa posição que se ocupa nesse campo. Ela funcio-

2. Foucault deixa claro: a "arqueologia não descreve disciplinas. Estas, no máximo, em seu desdobramento manifesto, podem servir de isca para a descrição das positividades; mas não lhe fixam os limites: não lhe impõem recortes definitivos; não se encontram inalteradas no fim da análise; não se pode estabelecer relação biunívoca entre as disciplinas instituídas e as formações discursivas" (Foucault, 1986, p. 202). 
naria como "matriz de sentido", e os falantes nela se reconheceriam, porque as significações ali lhes parecem óbvias, "naturais".

Considerando nossos atos ilocutórios - atos enunciativos, atos de fala -, podemos dizer que esses se inscrevem no interior de algumas formações discursivas e de acordo com um certo regime de verdade, o que significa que estamos sempre obedecendo a um conjunto de regras, dadas historicamente, e afirmando verdades de um tempo. As "coisas ditas", portanto, são radicalmente amarradas às dinâmicas de poder e saber de seu tempo. Daí que o conceito de prática discursiva, para Foucault, não se confunde com a mera expressão de idéias, pensamentos ou formulação de frases. Exercer uma prática discursiva significa falar segundo determinadas regras, e expor as relações que se dão dentro de um discurso. Quando a televisão, por exemplo, se apropria do discurso missionário do professor, fala e faz falar esse discurso, fala e faz falar um discurso segundo algumas de suas regras que fixaram enunciados sobre a figura da professora-mãe-doadora. Para o autor, portanto, o conceito de prática discursiva vincula-se diretamente a:

...um conjunto de regras anônimas, históricas, sempre determinadas no tempo e no espaço, que definiram, em uma dada época e para uma determinada área social, econômica, geográfica ou lingüística, as condições de exercício da função enunciativa. (Idem, p. I36)

Nesse caso faz-se necessário ressaltar que o enunciado, diferentemente dos atos de fala e mesmo das palavras, frases ou proposições, não é imediatamente visível nem está inteiramente oculto. Pode ocorrer de uma frase ou um ato ilocutório serem confundidos com certo enunciado, mas isso não quer dizer que "são" a mesma coisa. Assim, por exemplo, quando uma menina adolescente diz na televisão que só deixará de ser virgem quando encontrar "a pessoa certa", sua frase, em tal cena enunciativa, está investida de muito mais do que supõe uma simples coisa dita: ela põe em jogo um conjunto de elementos, referentes às "possibilidades" de aparecimento e delimitação daquele discurso. Enunciados dispersos como esse, extraídos e organizados a partir da análise de textos da mídia brasileira sobre o mundo adolescente, estão inscritos no dispositivo da sexualidade de nossa época, repartem-se segundo enunciados de determinadas formações discursivas sobretudo as relacionadas aos campos da medicina, da psicologia e da publicidade - e polemizam com enunciados de tantos outros discursos, como o discurso feminista, construído sobretudo a partir da década de 60. "Diz-se" um modo de existência sexual, "fala-se" um modo de ser mulher na juventude. "Deixar de ser virgem com a pessoa certa" é mais do que uma frase, é mais do que um desejo, é 
mais do que a promessa da menina diante das câmeras. Como descrever esse "mais", o enunciado e suas inúmeras relações, sem querer buscar algo que - quem sabe por uma maldade dos poderosos, por mecanismos de repressão e coação -, teria sido intencionalmente escondido?

Ora, por mais que o enunciado não seja oculto, nem por isso é visível; ele não se oferece à percepção como portador manifesto de seus limites e caracteres. É necessária uma certa conversão do olhar e da atitude para poder reconhecê-lo e considerá-lo em si mesmo. (Idem, p. I26)

Trata-se de um esforço de interrogar a linguagem - o que efetivamente foi dito - sem a intencionalidade de procurar referentes ou de fazer interpretações reveladoras de verdades e sentidos reprimidos. Simplesmente, perguntar de que modo a linguagem é produzida e o que determina a existência daquele enunciado singular e limitado. Deixar-se ficar nos espaços brancos, "sem interioridade nem promessa", como escreve Foucault. No caso do exemplo citado, trata-se de mapear os "ditos" sobre a sexualidade jovem, nas diferentes cenas enunciativas, multiplicando as relações aí sugeridas. Ao invés de buscar explicações lineares de causa e efeito ou mesmo interpretações ideológicas simplistas, ambas reducionistas e harmonizadoras de uma realidade bem mais complexa, aceitar que a realidade se caracteriza antes de tudo por ser belicosa, atravessada por lutas em torno da imposição de sentidos (Foucault, 1992). Multiplicar relações significa situar as "coisas ditas" em campos discursivos, extrair delas alguns enunciados e colocá-los em relação a outros, do mesmo campo ou de campos distintos. É operar sobre os documentos, desde seu interior, ordenando e identificando elementos, construindo unidades arquitetônicas, fazendo-os verdadeiros "monumentos". É perguntar: por que isso é dito aqui, deste modo, nesta situação, e não em outro tempo e lugar, de forma diferente? É investigar sobre as posições necessárias ao falante, para que ele efetivamente possa ser sujeito daquele enunciado: por exemplo, "a pessoa certa” seria uma necessidade só de meninas - e de meninas virgens? Como elas são incitadas a emitir esse enunciado ou a nele se reconhecerem plenamente? Os adolescentes do sexo masculino também se fazem sujeito dessa frase? Multiplicar relações, em contrapartida, é proceder a um levantamento da "memória" desse enunciado, acompanhá-lo como irrupção, como descontinuidade e como transformação. É tratar os enunciados na sua dispersão e na sua "pobreza", uma vez que poucas coisas são realmente ditas nesse grande murmúrio anônimo do "ser da linguagem". É o "ça parle" de Foucault, o "diz-se" que, segundo Deleuze, assume determinada dimensão conforme o corpus considerado. 
Estamos, então, capacitados a extrair - das palavras, frases e proposições - os enunciados, que não se confundem com elas. Os enunciados não são as palavras, frases ou proposições, mas formações que apenas se destacam de seus corpus quando os sujeitos da frase, os objetos da proposição, os significados das palavras mudam de natureza, tomando lugar no "diz-se", distribuindo-se, dispersando-se na espessura da linguagem. (Deleuze, 1991, p.29)

\section{EM QUE CONSISTE A HETEROGENEIDADE DISCURSIVA?}

Pluridiscursividade, heterogeneidade discursiva, interdiscurso são algumas palavras ou expressões que se referem, basicamente, à dispersão dos enunciados e, portanto, dos discursos; referem-se à idéia de que eles são, antes de mais nada, acontecimentos. $\bigcirc$ trabalho do pesquisador será constituir unidades a partir dessa dispersão, mostrar como determinados enunciados aparecem e como se distribuem no interior de um certo conjunto, sabendo, em primeiro lugar, que a unidade não é dada pelo objeto de análise. Na pesquisa sobre mídia e adolescência, aqui citada, identifico que o elemento unificador dos discursos não é o objeto "adolescência"; pelo contrário, percebo que um modo de ser adolescente foi construído pelo que se disse da adolescência, por meio de um conjunto de formulações bem datadas e localizadas; sendo assim, vou ater-me a documentos produzidos pelos meios de comunicação e a partir deles criar alguns "conjuntos arquitetônicos" - considerando que se constitui em nossos tempos um campo denominado, na falta de um vocabulário mais preciso, "discurso midiático", no qual o corpo jovem, especialmente o corpo da mulher jovem, adquire visível centralidade.

Construir unidades, porém, longe de significar uma operação de simplificação e assepsia de enunciados desorganizados, contaminados e por demais vivos, é um trabalho, como já dissemos, de multiplicação dessa realidade da coisa dita que, segundo Foucault, existe em sua "pobreza", como situação estreita e singular, que se torna sempre outra, pelo simples fato de alguma vez ter sido falada. Diria, num esforço de síntese, que o discurso, para o analista, é o lugar da multiplicação dos discursos, bem como o lugar da multiplicação dos sujeitos. É dessa dupla multiplicação que trataremos nos dois tópicos a seguir.

\section{Sobre o sujeito dos discursos}

A teoria do discurso está intimamente ligada à questão da constituição do sujeito social. Se o social é significado, os indivíduos envolvidos no processo de significação 
também o são e isto resulta em uma consideração fundamental: os sujeitos sociais não são causas, não são origem do discurso, mas são efeitos discursivos. (Pinto, 1989, p.25)

Descrever uma formulação enquanto enunciado não consiste em analisar as relações entre o autor e o que ele disse (ou quis dizer, ou disse sem querer); mas em determinar qual é a posição que pode e deve ocupar todo indivíduo para ser seu sujeito. (Foucault, 1986, p. 109)

Ao analisar um discurso - mesmo que o documento considerado seja a reprodução de um simples ato de fala individual -, não estamos diante da manifestação de um sujeito, mas sim nos defrontamos com um lugar de sua dispersão e de sua descontinuidade, já que o sujeito da linguagem não é um sujeito em si, idealizado, essencial, origem inarredável do sentido: ele é ao mesmo tempo falante e falado, porque através dele outros ditos se dizem. Esse caráter contraditório do sujeito rompe com uma tradição, cara não somente ao idealismo de algumas teorias da linguagem, como a desenvolvida por Benveniste, mas ainda àquelas concepções segundo as quais o eu seria absolutamente determinado de fora, dominado por um Outro que o constitui. Essa bipolaridade, como sabemos, dominou durante muito tempo as Ciências Humanas e dela se encontram vestígios até hoje em alguns discursos, como o da pedagogia, da sociologia e especialmente da militância política. $\bigcirc$ homem "sujeito da própria história", capaz de transformar o mundo a partir da tomada de consciência, reúne essas duas concepções: tudo se passaria como se, percebendo a dominação, a força do outro, o sujeito pudesse lutar e chegar, talvez um dia, à condição paradisíaca (e originária) de sujeito uno, pleno de poder.

Bem distinta dessa formulação, e fundada principalmente na idéia do conflito, da pluralidade de vozes que se enfrentam nos textos, é a concepção pela qual se introduz a presença do Outro no discurso. Mesmo que inicialmente ela tenha privilegiado certo determinismo, de fora para dentro, na verdade postula algo que, depois de Marx, não nos atrevemos a questionar: o homem é inconcebível fora das relações sociais que o constituem. Quando a filosofia da linguagem, de inspiração marxista, fez a tradução desse postulado, de modo especial com Bakhtin, que outros conceitos trouxe? Basicamente, uma teoria da polifonia, do diálogo, na qual fica entendido que há inúmeras vozes falando num mesmo discurso, seja porque o destinatário está ali também presente, seja porque aquele discurso está referido a muitos outros. Esse duplo cruzamento constituiria, nesse caso, a polifonia discursiva. Certamente essa descentração do sujeito, implícita na teoria marxista, pertence à 
mesma epistème ${ }^{3}$, dentro da qual se desenvolveu a psicanálise: o discurso do sujeito, para Freud, estaria sempre marcado pelo seu avesso, no caso, o inconsciente. Dividido, quebrado, descentrado, o sujeito se definiria por um inevitável embate com o outro que o habita. E, permanentemente, viveria a busca ilusória de tornar-se um. A linguagem seria a manifestação dessa busca, lugar em que o homem imagina constituir e expor sua própria unidade.

Ao contemplar a tensão entre o Eu e o Outro, nos discursos, Foucault traça um caminho bem diferente para a compreensão do sujeito: afasta-se desse espaço em que se relacionam sujeitos individuais e invade o espaço de uma relação mais ampla, baseada na noção de dispersão do sujeito. A heterogeneidade discursiva está diretamente ligada a essa dispersão, já que nos discursos sempre se fala de algum lugar, o qual não permanece idêntico: falo e, ao mesmo tempo, sou falado; enuncio individualmente, de forma concreta, constituindo-me provisoriamente um, ambicionando jamais cindir-me, porém a cada fala minha posiciono-me distintamente, porque estou falando ora de um lugar, ora de outro, e nesses lugares há interditos, lutas, modos de existir, dentro dos quais me situo, deixando-me ser falado e, ao mesmo tempo, afirmando de alguma forma minha integridade. Aliás, sem essa afirmação, meu texto se perderia na desordem e na ausência de fronteiras.

Foucault multiplica o sujeito. A pergunta "quem fala?" desdobra-se em muitas outras: qual o status do enunciador? Qual a sua competência? Em que campo de saber se insere? Qual seu lugar institucional? Como seu papel se constitui juridicamente? Como se relaciona hierarquicamente com outros poderes além do seu? Como é realizada sua relação com outros indivíduos no espaço ocupado por ele. Também cabe indagar sobre o "lugar de onde fala", o lugar específico no interior de uma dada instituição, a fonte do discurso daquele falante, e sobre a sua efetiva "posição de sujeito"- suas ações concretas, basicamente como sujeito incitador e produtor de saberes. É assim que se destrói a idéia de discurso como "expressão" de algo, tradução de alguma coisa que estaria em outro lugar, talvez em um sujeito, algo que preexiste à própria palavra.

Imagino que os sujeitos adolescentes que falam ou são falados na mídia dispersam-se de inúmeras formas: de maneira geral, sua multiplicação se faz por meio das diversas modalidades enunciativas do discurso da televisão, das revistas e

3. Entendo esse conceito como Foucault o formulou em A Arqueologia do saber. como o conjunto das relações que permitem "compreender o jogo das coações e das limitações que, em um momento determinado, se impõem ao discurso" (Foucault, 1986, p. 217) 
dos jornais. Cartas, depoimentos, testes, questionários, entrevistas, crônicas, reportagens, fotos, textos de ficção - gravados em páginas impressas ou em fitas magnéticas de vídeo e reproduzidos para veiculação massiva - constituem uma base material sobre a qual e a partir da qual se dispersam inúmeras "adolescências": de um lado, meninas quase anônimas que perguntam sobre o incompreensível mundo do sexo, meninas-modelo que revelam o dia-a-dia exercitado e controlado da manutenção de um corpo esguio, astros precoces do espetáculo biografados na limitada trajetória de suas vidas, meninos que respondem a entrevistas sobre a namorada ideal, meninas trabalhadoras desde a infância que deixam registrados seus sonhos em reportagens "sociais", adolescentes de ambos os sexos, marginais do tráfico de drogas, do roubo e do assassinato; de outro, o coro das vozes adultas que, afinadas ou dissonantes, são também sujeitos de um discurso da adolescência, por indagá-la, ouvi-la, fazê-la falar e a ela devolver um discurso em geral normalizador e sempre constitutivo - o coro dos locutores, apresentadores de TV, colunistas de jornais e revistas, sexólogos, médicos, psiquiatras e psicólogos, os peritos da saúde física e mental, os especialistas do amor e da beleza.

"Fala-se" uma adolescência de diferentes maneiras, e há discursos que não podem ser assinados por todos igualmente: o depoimento da atriz e modelo de sucesso sobre sua gravidez precoce reveste-se de uma permissividade que é negada à menina de subúrbio - cuja voz é captada pela reportagem especial do grande diário -, e a quem se dirige o discurso do demógrafo, da socióloga e da psicóloga, atento ao controle da sexualidade e da reprodução humana nas camadas populares. Da mesma forma, há uma espécie de lei de "propriedade dos discursos": só alguns têm o direito de falar com autoridade sobre a sexualidade dos adolescentes; não são todos que têm competência para compreender os enunciados médicos, por exemplo, nas respostas às cartas dos leitores de jornais e revistas; um restrito grupo tem capacidade para investir o discurso do aperfeiçoamento do corpo em práticas correspondentes. Mas, como veremos mais adiante, se estamos ocupados com os discursos produzidos e veiculados pelos meios de comunicação, temos um problema específico a tratar: independentemente do entendimento imediato dos textos por segmentos do público e da maior ou menor decodificação de frases ou imagens, o mais importante é compreender esses discursos no limite de seus efeitos, os quais poderão relacionar-se inclusive ao "respeito", por exemplo, em relação ao especialista, produzido sobre o espectador que não entendeu certa formulação. A idéia inicial do sujeito como "efeito discursivo" reafirma-se aqui uma vez mais. 
Diversas posições e formas de subjetividade, portanto, podem ser lidas como efeitos de um campo enunciativo, a partir apenas do critério das modalidades, como referimos, desde que se descrevam as regularidades, as freqüências, a distribuição dos elementos, em torno da pergunta sobre esse "lugar vazio" dos discursos, que é o sujeito dos enunciados.

O discurso, assim concebido, não é a manifestação, majestosamente desenvolvida, de um sujeito que pensa, que conhece, e que o diz: é, ao contrário, um conjunto em que podem ser determinadas a dispersão do sujeito e sua descontinuidade em relação a si mesmo. É um espaço de exterioridade em que se desenvolve uma rede de lugares distintos. (Foucault, 1986, p.6I-2)

\section{Cruzamento de identidades e diferenças: o interdiscurso}

Espaço de dissensões e oposições múltiplas, a formação discursiva faz-se de asperezas e estridências, mais do que de harmonias e superfícies lisas. Inteiramente vivo, o campo enunciativo acolhe novidades e imitações, blocos homogêneos de enunciados bem como conjuntos díspares, mudanças e continuidades. Tudo nele se cruza, estabelece relações, promove interdependências. O que é dissonante é também produtivo, o que semeia a dúvida é também positividade crítica. Mero jogo de palavras? Talvez não. Quando Foucault diz que os enunciados são povoados, em suas margens, de tantos outros enunciados, afirma a ação do interdiscurso, da complementaridade e da luta dos diferentes campos de poder-saber, afirma a importância da análise arqueológica, segundo a qual se despreza a solenidade da ciência, para privilegiar textos e gestos nem tão inéditos assim, enunciados miméticos, banais e discretos, ao lado das grandes e luminosas originalidades.

Talvez uma das operações mais ricas e fundamentais, sugerida por Foucault para a análise dos enunciados, seja a de complexificá-los no sentido de indagar a respeito de seus "espaços colaterais". Em que consiste essa operação? Tomando outra vez o exemplo da virgindade e da "pessoa certa", poderíamos dizer que o enunciado aí considerado se situa em relação a uma constelação de formulações. Esse enunciado se inscreve, por exemplo, no interior das modalidades enunciativas dos diferentes meios de comunicação (a "novela das oito" ou as cartas à sexóloga do jornal, entre tantas outras) -, ou seja, diferencia-se conforme o meio e a modalidade enunciativa; também se situa entre os enunciados sobre comportamento sexual jovem, produzidos e em circulação entre campos como o da psicologia, da medicina e da educação sexual; tem uma positividade específica, na medida de sua 
repercussão, de seu alcance, das possibilidades de aceitação ou questionamento a afirmação da opção pela virgindade, num programa de TV ao vivo, tem conseqüências quase imediatas; finalmente, é marcado também pelo conjunto de formulações que the conferem algum status, seja porque tem respaldo "científico", seja porque a posição do sujeito enunciativo assim o constitui. Tudo isso "povoa" o enunciado e deve ser descrito, justamente porque

...[não há] enunciado livre, neutro e independente; mas sempre um enunciado fazendo parte de uma série ou de um conjunto, desempenhando um papel no meio dos outros, neles se apoiando e deles se distinguindo: ele se integra sempre em um jogo enunciativo, onde tem sua participação, por ligeira e ínfima que seja. [...] Não há enunciado que não suponha outros; não há nenhum que não tenha, em torno de si, um campo de coexistências. (Foucault, 1986, p. II4)

Buscar a configuração interdiscursiva, portanto, não remete àquela tentativa de tudo explicar, de dar conta do amplo sistema de pensamento de uma época. Longe disso, remete a um rico e duro trabalho de multiplicação dos discursos ou, simplesmente, de complexificação do conhecimento, no mesmo sentido definido por Edgar Morin, sobretudo em sua conhecida obra La méthode ${ }^{4}$. Segundo Foucault, cada formação discursiva entra simultaneamente em diversos campos de relações, e em cada lugar a posição que ocupa é diferente, dependendo do jogo de poderes em questão. Guardadas as proporções, é o mesmo movimento das

4. Em O problema epistemológico da complexidade, livro que reproduz um debate de professores universitários portugueses com o pensador francês Edgar Morin, realizado em Lisboa no ano de 1983, o autor de La méthode (obra em quatro volumes: ver Morin, 1977, 1980, 1986, 1991) analisa a crise atual dos fundamentos do conhecimento científico - a crise da objetividade dos enunciados científicos e da coerência lógica das teorias correspondentes , argumentando a favor da idéia de complexidade do pensamento. Segundo Morin, complexidade não se confunde com "complicação"; aponta, antes, uma exigência política e social de nossos tempos, em que se questiona a mutilação do pensamento e se busca uma nova forma de lidar com a "dificuldade da palavra que quer agarrar o inconcebível e o silêncio", uma nova forma de compreender a relação entre o todo e as partes, que na realidade sempre se implicam mutuamente. Enfim, complexificar significa aceitar a própria dificuldade de pensar, "porque o pensamento é um combate com e contra a lógica". Tanto quanto Bachelard, Canguilhem e Foucault, Morin pensa sobretudo a descontinuidade do homem, dos fatos e da história. Ele diz: "é necessário ver não só o tecido determinista mas também as falhas, os buracos, as zonas de turbulência, os cachões da cultura onde, efectivamente, brota o novo" (Morin, s.d., p. 28). E mais: "A vida alimenta-se das impurezas, ou melhor, a realidade e o desenvolvimento da ciência, da lógica, do pensamento têm necessidade destas impurezas" (p. 34). 
posições do sujeito discursivo, como vimos anteriormente. Adentrar esse "emaranhado de interpositividades" é a proposta que o filósofo e pesquisador nos faz, no sentido de, através de uma análise comparativa, repartirmos em figuras diferentes a diversidade dos enunciados e dos discursos (Foucault, 1986, p. 183).

Em outras palavras, considerar a interdiscursividade significa deixar que aflorem as contradições, as diferenças, inclusive os apagamentos, os esquecimentos; enfim, significa deixar aflorar a heterogeneidade que subjaz a todo discurso. Maingueneau chega a radicalizar: para a análise do discurso, segundo ele, haveria quase um primado do interdiscurso sobre o discurso, já que a unidade a ser analisada consistiria exatamente num espaço de trocas entre vários discursos. Penso que, ao assumir também esse ponto de vista como básico nas investigações sobre mídia e educação - usadas neste trabalho para exemplificar a teoria do discurso em Foucault -, tenho condições de apanhar mais consistentemente os discursos sobre os quais me debruço, até porque investigo materiais bastante ricos no que se refere às lutas entre os vários campos - lutas que tomam forma em uma infinidade de produtos como seriados de TV, entrevistas, reportagens, documentários, clips, debates ao vivo, cartas, peças publicitárias.

Ora, a mídia, ao mesmo tempo que é um lugar de onde várias instituições e sujeitos falam - como veículo de divulgação e circulação dos discursos considerados "verdadeiros" em nossa sociedade -, também se impõe como criadora de um discurso próprio. Porém, pode-se dizer que, nela, talvez mais do que em outros campos, a marca da heterogeneidade, além de ser bastante acentuada, é quase definidora da formação discursiva em que se insere. Poderíamos dizer que hoje praticamente todos os discursos sofrem uma mediação ou um reprocessamento através dos meios de comunicação. Basta lembrar o discurso político na época de eleições: nenhum candidato, nenhum partido prescinde, em nossos dias, do complexo mundo da imagem, do marketing, da necessidade de ser notícia. Isso é válido para outros tantos campos: o médico, o religioso, e assim por diante, sem falar daqueles que praticamente "vivem" dos media - a moda e a música, por exemplo. Está em jogo, nessa pluridiscursividade do social, luta pela imposição de sentido, a luta entre vários discursos, na conquista de novos sujeitos. Um dos campos que mais explicitamente expõe a luta entre discursos é o da publicidade, e é nele que se torna bem visível a importância da multiplicação tanto de sujeitos quanto de discursos. Na busca permanente da adesão de novos sujeitos, o discurso publicitário reprocessa enunciados de fontes variadas; porém, como os indivíduos podem ser sujeitos de vários discursos, produz-se a fragilidade de cada um 
desses campos, considerados isoladamente. Daí a "necessidade da luta interpelatória constante" (Pinto, 1989, p.38) .

Se dentro da mesma formação coexistem enunciações heterogêneas - como vemos ocorrer com o discurso psiquiátrico, no exemplo dado por Foucault (1978) em História da loucura -, imagine-se então no discurso da mídia, que não se fundamenta em apenas uma disciplina, mas em várias (ligadas ao jornalismo, à publicidade, às artes plásticas, ao cinema, às tecnologias de informação, à teoria da comunicação e assim por diante). Mais ainda se multiplicam nela os discursos, as criações, recriações, transformações, analogias e adaptações de enunciados distintos, em direção a um novo discurso com características próprias. Eu diria que atingimos um tempo em que cada vez mais essa discursividade toma corpo, define-se, impõe-se como básica ao funcionamento geral da sociedade contemporânea. Talvez o que esteja faltando é descrever os limites, a configuração desse discurso, suas regularidades, que hoje se mostram bem mais visíveis.

Imagino que as reflexões geradas pela análise feita na investigação aqui usada como exemplificação amplie a compreensão não só de como funciona o campo específico dos meios de comunicação, mas principalmente de como se operam, no nível dos enunciados, as inter-relações discursivas. Vejamos. $\bigcirc$ espaço discursivo ${ }^{6}$ por mim delimitado na pesquisa em questão - genericamente, o que a mídia "fala" sobre adolescência - foi selecionado do interior do campo discursivo dos meios de comunicação social, com o fim de atingir um objetivo central: descrever os enunciados que nossa sociedade, nesses últimos anos, tem construído sobre a adolescência. A suposição é que haveria uma espécie de fusão entre os valores entronizados pela mídia (o sucesso individual, certo tipo de beleza física, um modo de vida baseado na cultura do corpo e no consumo permanente de bens mate-

5. Na primeira parte do livro Com a palavra o Senhor Presidente Sarney, Céli Regina Jardim Pinto apresenta o conceito de discurso articuladamente às questões do poder e da constituição de sujeitos sociais, desenvolvendo reflexões fundamentais para este trabalho, particularmente no que se refere a uma compreensão mais ampla da discursividade da mídia e da publicidade na produção de subjetividades.

6. Meu recorte, cabe referir aqui, é feito segundo a classificação proposta por Maingueneau, quanto à amplitude dos conjuntos discursivos: o autor distingue universo discursivo - correspondente a todas as formulações discursivas que circulam numa dada conjuntura; campo discursivo - o grupo das formações discursivas em luta e espaço discursivo - o subconjunto de determinado campo discursivo, no qual é possível registrar presença de pelo menos duas formações, cujo embate é fundamental para a eficácia (e compreensão) dos discursos considerados (Maingueneau, 1993, p. I16-7). 
riais, entre tantos outros) e aqueles pelos quais se passa a definir o que seria um adolescente "ideal" para a classe média, ou seja, haveria uma importante intersecção entre mídia e adolescência. Mas, o mais importante a destacar é que, se cada discurso é remetido por ele mesmo a tantos outros, os discursos incorporados pela mídia, a partir de outros campos - mormente os da medicina, da pedagogia, da psicologia, da psicanálise -, também eles, ao entrarem na cena midiática, ao tomarem forma dentro desse campo específico da comunicação social, sofrem um tratamento que os retira de seu habitat e que, ao mesmo tempo, reforça a autoridade própria de cada um, pela importância que têm numa determinada formação social. Finalmente, caberia ainda dizer que o próprio recorte feito pelo pesquisador é também um "fato de discurso" e, como tal, introduz mais um dado que amplia e dinamiza o que por definição é já heterogêneo.

$\bigcirc$ tratamento segundo o qual os discursos são transformados e incorporados não deve ser visto de modo compacto, como se estivéssemos em busca de uma totalidade bem-acabada, definidora de uma dada discursividade; pelo contrário, é preciso considerar os diferentes momentos de enunciação e analisá-los criticamente como objetos vivos, pois haveria uma real impossibilidade de separar a interação dos discursos (interdiscursividade) do funcionamento intradiscursivo (isto é, a dinâmica dos enunciados dentro da mesma formação), o que, segundo Maingueneau, está diretamente relacionado ao caráter de diálogo, permanentemente vivo em qualquer enunciado ${ }^{7}$.

\section{A TEMPORALIDADE DOS ENUNCIADOS}

Foucault é um dos pensadores que mais soube tratar teoria e prática sem colocá-las em campos separados. E ele o faz duplamente: de um lado, talvez por uma necessidade vital, afirma a precariedade do seu próprio discurso, vive-o como processo, como possibilidade de transformação, como desejo de distanciar-se de si mesmo e empreender um esforço de pensar diferente do que pensa; de outro, no tratamento dos dados e no trabalho sobre os documentos, Foucault "aplica"

7. Aliás, cabe salientar que a análise do discurso confere a diálogo um sentido mais amplo do que aquele comumente atribuído a essa palavra. Tal sentido, referido pela primeira vez na obra de Bakhtin, como vimos anteriormente, leva a considerar que, do ponto de vista discursivo, "não há enunciado desprovido da dimensão dialógica, pois qualquer enunciado sobre um objeto se relaciona com enunciados anteriores produzidos sobre este objeto. Assim, todo discurso é fundamentalmente dialógico" (Brandão, 1993, p. 89). 
esse mesmo modelo, mostrando que há antes "possibilidades de discursos" e que os enunciados são sempre históricos, não só em relação às suas condições de emergência como às funções por eles exercidas no interior de práticas não discursivas.

"O discurso não tem apenas um sentido ou uma verdade, mas uma história", escreve Foucault (1986, p. I 46). Ora, dizer que o discurso é sobretudo histórico implica necessariamente falar na relação entre o discursivo e o não-discursivo, na impossibilidade de separar o lado de dentro do lado de fora dos enunciados, significa falar na "economia" dos discursos - em sua produtividade visível -, enfim, na relação entre pensamento e vida, poder e saber, continuidade e descontinuidade da história, temas tão caros ao autor de As Palavras e as coisas. Vejamos uma das definições de discurso em que Foucault consegue reunir todos os elementos aqui referidos, principalmente a intrincada relação entre teoria e prática, discurso e poder, enunciado e história - assuntos deste artigo. Numa das brilhantes passagens de A Arqueologia do saber, o autor situa discurso como

...um bem - finito, limitado, desejável, útil - que tem suas regras de aparecimento e também suas condições de apropriação e de utilização; um bem que coloca, por conseguinte, desde sua existência (e não simplesmente em suas "aplicações práticas") a questão do poder; um bem que é, por natureza, o objeto de uma luta, e de uma luta política. (p. 139)

Mais uma vez, é preciso que se diga: Foucault escreve essa definição de discurso baseado num anterior e meticuloso trabalho de pesquisa; o que aí está dito ele o demonstrou em cada página de sua vasta obra. Em A História da loucura, por exemplo, a análise do discurso do século XVIII sobre a loucura permitiu-lhe assinalar a descontinuidade entre a época clássica e a modernidade: ele descobriu a grande ruptura que então se estabeleceu, referida não só ao discursivo (o conhecimento sistemático sobre a loucura) como ao não-discursivo (as práticas médicas correspondentes). Através da análise de inúmeros documentos, Foucault descreve as transformações do discurso sobre a loucura, a emergência de um conceito como "doença mental" - inexistente até antes da Revolução Francesa - e a relação entre uma série de práticas ligadas ao enclausuramento do louco e à instauração de uma nova ordem social. Descobre, enfim, como diz Roberto Machado , "uma

8. Os comentários deste parágrafo sobre História da loucura sintetizam algumas das idéias desenvolvidas por Roberto Machado (1995). 
crescente subordinação da loucura à razão", isto é, sua total dependência em relação à ciência médica. Pelas práticas psiquiátricas, a loucura é medicalizada e passa a penetrar a intimidade da alma humana. É a loucura tutelada pela razão. É a ciência "corrigindo" a vida nesse longo e interminável processo de racionalização que nos constitui como "homem ocidental" na modernidade. Foucault nos ensina, com Canguilhem, Bachelard, Koyré, que "ciência é relação", e que é necessário estar atento às rupturas operadas nos discursos e nas práticas; com Nietzsche, mostra como não é preciso partir das grandes verdades científicas para fazer história e como é preciso questionar o conhecimento que cada vez mais tenta se apoderar do âmago das vidas e do real. Tudo isso em nome de quê? Da saudação da beleza trágica da vida.

Nessa síntese de História da loucura, tentamos reunir o máximo de elementos de um projeto, ao mesmo tempo teórico e prático, intelectual e existencial, para exemplificar a questão da temporalidade na análise dos discursos. Essa temporalidade, como se vê, precisa ser entendida para além da idéia de que os discursos sempre são ditos num determinado tempo e num determinado lugar; para mergulhar nela, é preciso vê-la através dos documentos escolhidos, das práticas a que os textos se referem, da formação social em questão, da trajetória dos conceitos envolvidos e ainda do próprio posicionamento do pesquisador. Para Foucault, a análise arqueológica deve principalmente dar conta de como se instaura certo discurso, quais suas condições de emergência ou suas condições de produção. E é nesse sentido que essa análise deverá fazer aparecer os chamados "domínios não discursivos" a que os enunciados remetem e nos quais eles de certa forma "vivem" - as instituições, os acontecimentos políticos, os processos econômicos e culturais, toda a sorte de práticas aí implicadas. Tais domínios, porém, não podem ser vistos como "expressão" de um discurso, nem como seus determinantes, mas como algo "que faz parte de suas condições de emergência" (Foucault, 1986, p. 187).

Que isso quer dizer? Em primeiro lugar, que nessa relação tão estreita entre discurso e práticas não discursivas, há mútua implicação, jamais linearidade explicativa. Se hoje se produz toda uma discursividade, por exemplo, sobre a "juventude da mulher de 40 anos", isso não só remete ao fato de que ocorre uma transformação do discurso feminista da década de 60, como deve levar-nos a ver como esse discurso está articulado a estratégias de poder, que se voltam para o corpo da mulher e multiplicam técnicas e procedimentos disciplinares, devidamente validados pela suposição de atingível padrão de vida e beleza. Tal discurso certamente 
não existe sem as revistas, sem a televisão, sem a publicidade; também não existe sem as academias de ginástica, a indústria da moda, e está relacionado às lutas das mulheres em torno de uma série de conquistas: descriminalização do aborto, exercício de funções públicas e políticas, e assim por diante, ou seja, nessa relação necessária entre o discursivo e o não-discursivo, o fato de algumas instâncias serem vistas didaticamente como "suportes" de enunciados - porque a mulher deve ser bela e jovem, criam-se academias ou especialidades médicas e, através destas, o projeto se realizaria - precisa ser compreendido de modo mais complexo. $\bigcirc$ discurso ele mesmo está em constante transformação por "exercitar-se" nesses espaços todos, e tais lugares, por sua vez, não são sempre os mesmos, desde que os sujeitos e as instituições se reconhecem nesse discurso.

Uma prática discursiva, segundo Foucault, "toma corpo em técnicas e efeitos" (1986, p.220). E como se trata de uma via de mão dupla, pode-se dizer que as técnicas, as práticas e as relações sociais, em que estão investidos os enunciados, constituem-se ou mesmo se modificam exatamente através da ação desses mesmos enunciados. Com isso Foucault quer dizer que "as coisas não têm o mesmo modo de existência, o mesmo sistema de relações com o que as cerca, os mesmos esquemas de uso, as mesmas possibilidades de transformação depois de terem sido ditas" (I 986, p. | 43). Não sendo as mesmas depois de ditas, as coisas têm uma existência precária, escorregadia, uma dispersividade que o arqueologista só poderá captar no momento em que se dispuser a descrever o conjunto das relações postas em jogo num determinado discurso. Ele não vai encontrar, "por baixo" dos textos, uma vida que fervilha, a vida "ainda não capturada": vai deter-se na construção de um feixe de relações, no desenho que articula enunciados e práticas, enunciados e técnicas, sobre um dado objeto; o mapa certamente apontará para regiões exteriores, para lugares maiores de "aplicação" de um discurso (as instituições, por exemplo). Todas essas relações, porém, como lembra Foucault, "por mais que se esforcem para não serem a própria trama do texto, não são, por natureza, estranhas ao discurso" (1986, p.84). Em outras palavras, as práticas não discursivas são também parte do discurso, à medida que identificam tipos e níveis de discurso, definindo regras que ele de algum modo atualiza.

Eu acrescentaria neste trabalho mais uma idéia para a compreensão do cruzamento e da interdependência de práticas discursivas e não discursivas: ela diz respeito também à positividade dos discursos na história dos corpos. O que fomos e o que somos, o que foram e o que disseram nossos ancestrais, tudo isso marca nossos corpos, penetra-os e os produz, para o bem ou para o mal. Herdeiro de 
Nietzsche, Foucault ensina um modo de fazer história, fundamentalmente ocupado com uma genealogia que se volta para a observação dos corpos, para a apreensão das descontinuidades como coisas vividas e inscritas nesse lugar único e irredutível dos indivíduos. Se os acontecimentos são apenas marcados pela linguagem e dissolvidos pelas idéias, há um lugar em que definitivamente se inscrevem: a superfície dos corpos. Assim, quando o arqueologista ressalta a dinâmica dos lados de dentro e de fora dos discursos, de certo modo está afirmando sua vocação de genealogista: para ele, os sujeitos são efeitos de discursos, e esses efeitos - produzidos no interior de inúmeras e bem concretas relações institucionais, sociais e econômicas - não existem senão nos corpos:

...sobre o corpo se encontra o estigma dos acontecimentos passados do mesmo modo que dele nascem os desejos, os desfalecimentos e os erros; nele também eles se atam e de repente se exprimem, mas nele também eles se desatam, entram em luta, se apagam uns aos outros e continuam seu insuperável conflito. (Foucault, 1992, p.22)

Tornemos, no entanto, esse raciocínio mais complexo, voltando a discutir a importância dada por Foucault ao que ele chamou de "práticas", sejam elas discursivas ou não discursivas. Na entrevista a Dreyfus e Rabinow (1995) - publicada originalmente sob o título "À propos de la généalogie de l'éthique: un aperçu du travail en cours" -, Foucault, discorrendo sobre a milenar prática da littérature du moi ("escrita de si"), mais uma vez distingue discurso e sistemas simbólicos, admitindo que estes, obviamente, sejam também ativos na produção do sujeito. Porém, mais uma vez afirma: embora seja verdade que o sujeito é constituído simbolicamente, ele é sobretudo constituído por práticas reais, historicamente analisáveis. Há toda uma tecnologia de produção do sujeito que atravessa, perturba e até desestabiliza os sistemas simbólicos, ao mesmo tempo que deles se serve (Dreyfus, Rabinow, 1984, p.344). Importa, portanto, deter-se sobre essas práticas - discursivas e não discursivas -, para compreender a rede diferenciada de poderes e saberes que nos produzem.

Tomemos novamente o exemplo da "jovem mulher de 40": esse discurso não será analisado nem como "expressão de uma conjuntura" nem idealmente como mera criação simbólica. Associada a uma série de conquistas sociais, essa proliferação de textos sobre a mulher - convidada a ultrapassar a antiga posição romântica, a falar de seus desejos sexuais e seu prazer e a buscar uma maturidade cheia de beleza e atrativos - deve ser analisada a partir das práticas a que esse discurso está associado. Tais práticas, por sua vez, expõem uma série de lutas, a 
começar pela luta básica relativa ao confronto de homens e mulheres e se tornam visíveis na superfície dos corpos femininos. Sabendo-se que vários campos, como o da moda, da medicina estética, ginecológica e endocrinológica, e da psicologia, entre outros, disputam a hegemonia de uma discursividade sobre essa mulher, trata-se de desenhar as margens dos enunciados aí produzidos e fazer aparecerem as diferenças, as congruências e as comunicações, ocupando-se principalmente em descrever as práticas efetivas a que eles fazem referência - práticas que conformam cotidianos, definem projetos de vida, moldam, transformam e desenham os corpos. Se a mulher fala e é falada, é porque, como os "homens infames" de que nos fala Foucault, ela de algum modo se confronta com o poder. Não um poder que somente cerceia, desmantela, vigia, surpreende ou proíbe; mas um poder que suscita, incita e produz; um poder que "não é apenas olho e ouvido", mas que sobretudo "faz agir e falar", como diz o filósofo (1992a, p. 123).

○ que está em jogo no método arqueológico, quando se fala na íntima e necessária relação entre o discursivo e o não-discursivo, é que ele se concentra sobre o domínio de coisas efetivamente ditas ou escritas, importando descrever justamente de que modo elas se inscrevem no interior das formações discursivas, isto é, no sistema relativamente autônomo dos atos do discurso, em que são produzidas essas "coisas ditas" (Dreyfus, Rabinow, 1984, p.78). Esse "modo" diz respeito a um processo permanente de transformação do sistema de relações em que os textos analisados estão envolvidos. Como já se disse, os enunciados, depois de ditos, depois de instaurados numa determinada formação, sofrem sempre novos usos, tornam-se outros, exatamente porque eles constituem e modificam as próprias relações sociais. Descrevendo, portanto, esse universo de "diferenças", damos conta da formação e da transformação dos discursos, que é o objetivo principal da análise.

Por onde começar? O ponto de partida talvez seja a atenção ao presente, a atenção a um "diz-se", ao "ça parle" de determinado campo de saber, aos "murmúrios" de nossa época, para só então definir um corpus que permita apanhar a história de um determinado objeto. Se essa atenção me conduziu a investigar a evidente centralidade da figura adolescente nos textos da mídia, em nossa época, tinha por sabido que esse discurso, como qualquer outro, tem também uma história. Sabia, por exemplo, que foi a partir do início do século $X X$ que se começou a falar de "adolescente" como classe de idade, fase de transição entre a infância e a idade adulta. Mas que enunciados foram registrados sobre essa categoria - "adolescência” -, desde que foi criada? De que posições e de que lugares se falava nos 
adolescentes, nas primeiras décadas do século? Quais os momentos de transformação do discurso que se ocupa do jovem, desde esse tempo até nossos dias? Que dizem os textos deste final de século, tão ocupado com a adolescência? Que rupturas instauram? Que efeitos esse discurso vem operando sobre os corpos, especialmente nos nossos dias, em que não só os adolescentes mas amplas faixas da população aceitam submeter-se ao discurso da "eterna juventude", como se o envelhecimento e a morte já não fossem "fatos da vida", mas processos totalmente controláveis e até mesmo indesejáveis?

Baseado nos estudos de Canguilhem, Foucault ensina que os conceitos sofrem constantes deslocamentos e transformações e que a trajetória de um conceito é na verdade a história de seus diversos campos de constituição e de validade, das sucessivas regras de uso nos diferentes meios teóricos em que ele foi elaborado. Desse ponto de vista, não haveria nem conceitos nem categorias "essenciais" ou ideais - quais portos de ancoragem, lugares de repouso para o pesquisador. E, sim, descontinuidades que nos compelem a ver e pensar a diferença, os afastamentos, as dispersões, sem ter medo de "pensar o outro no tempo do nosso próprio pensamento", como diz Foucault na célebre introdução de A Arqueologia do saber. Nesse sentido, o caminho não é buscar, indefinidamente, um ponto originário e saber onde tudo começou. As datas e locais que fixamos não significam pontos de partida nem dados definitivos; são, antes, referências ligadas às condições de produção de um dado discurso, que se enuncia diferente, que é outro em cada um desses lugares e instantes. Não se trata, de forma alguma, de fazer uma interpretação cronológica nem de ir situando os elementos, como se fosse possível uma seqüencialidade. Uma coisa é tratar de domínios como os de atualidade, memória e antecipação; outra é afirmar que há um "antes-agora-depois", disposto numa linearidade fundamental. Aqueles domínios, considerados e operacionalizados, permitirão caracterizar o que se repete, o que instaura rupturas, o que se transforma, o que está nas fronteiras de um determinado tempo.

Para o analista, é importante observar, como anunciamos, que a modificação dos enunciados implica a existência de um acúmulo, de uma memória, de um conjunto de já-ditos. Dessa forma, qualquer seqüência discursiva da qual nos ocupemos poderá conter informações já enunciadas; haveria um processo de reatualização do passado nos acontecimentos discursivos do presente. Essas redes de formulação - o tecido constituído pelo discurso de referência e pelo já-enunciado - permitiriam descrever efeitos de memória, ou seja, redefinições, transformações, esquecimentos, rupturas, negações, e assim por diante. Não se trata de 
acionar uma memória psicológica, nem de "despertar os textos de seu sono", como diz Foucault. É preciso levantar os temas relacionados aos "esquecimentos" e mostrar qual o modo de existência que caracteriza aqueles enunciados, os quais estão, sempre, diretamente investidos em técnicas e práticas, isto é, em relações sociais.

\section{CONCLUSÃO}

Procurei, neste artigo, expor a teoria de Foucault sobre o discurso, demonstrando de que modo o autor ensina aos pesquisadores um modo de investigar não "o que está por trás" dos textos e documentos, nem "o que se queria dizer" com aquilo, mas sim descrever quais são as condições de existência de um determinado discurso, enunciado ou conjunto de enunciados. Suspendendo continuidades, acolhendo cada momento do discurso e tratando-o no jogo de relações em que está imerso, é possível levantar um conjunto de enunciados efetivos, em sua singularidade de acontecimentos raros, dispersos e dispersivos e indagar: afinal, por que essa singularidade acontece ali, naquele lugar, e não em outras condições?

Em síntese, partindo de que não se pode falar de qualquer coisa em qualquer época, o que afirmei, a partir de Foucault, é que um determinado objeto (como o conjunto de enunciações sobre a professora dadivosa ou a adolescente virgem) existe sob condições "positivas", na dinâmica de um feixe de relações, e que há condições de aparecimento histórico de um determinado discurso, relativas às formações não discursivas (instituições, processos sociais e econômicos). Tudo isso pode ser aprendido e descrito a partir dos próprios textos; a partir deles, é possível destacar as regras pelas quais o jogo de relações entre o discursivo e o não discursivo, em uma determinada época, fazem aparecer aquele objeto, e não outro, como objeto de poder e saber (o objeto virgindade adolescente, o objeto professora missionária, ou ainda o objeto mulher jovem de 40 anos, conforme os exemplos citados).

A compreensão da temporalidade dos discursos, como vimos aqui, talvez possa deixar um pouco mais clara a preocupação de Foucault com a "raridade" não só dos enunciados, mas dos próprios fatos humanos. Essa atenção ao que poderia ser "outro" é básica para o arqueologista. O historiador Paul Veyne explica que a afirmação de que os fatos humanos são raros significa, no pensamento foucaultiano, que eles: 
...não estão instalados na plenitude da razão, há um vazio em torno deles para outros fatos que o nosso saber nem imagina; pois o que é poderia ser diferente; os fatos humanos são arbitrários, no sentido de Mauss, não são óbvios, no entanto parecem tão evidentes aos olhos dos contemporâneos e mesmo de seus historiadores que nem uns nem outros sequer o percebem. (Veyne, 1982, p. I52, grifos meus)

Convite de Foucault é que, através da investigação dos discursos, nos defrontemos com nossa história ou nosso passado, aceitando pensar de outra forma o agora que nós é tão evidente. Assim, libertamo-nos do presente e nos instalamos quase num futuro, numa perspectiva de transformação de nós mesmos. Nós e nossa vida, essa real possibilidade de sermos, quem sabe um dia, obras de arte.

\section{REFERÊNCIAS BIBLIOGRÁFICAS}

BRANDÃO, H. Introdução à análise do discurso. Campinas: Unicamp, 1993.

DELEUZE, G. Conversações. 1972-1990. Rio de Janeiro: Ed. 34, 1992.

Foucault. São Paulo: Brasiliense, 1991.

DREYFUS, H.; RABINOW, P. Michel Foucault. un parcours philosophique: au-delà de l'objectivité et de la subjectivité. Paris: Gallimard, 1984.

Sobre a genealogia da ética: uma revisão do trabalho. In: DREYFUS, $H_{\text {.; }}$ RABINOW, P. Michel Foucault. uma trajetória filosófica. Para além do estruturalismo da hermenêutica. Rio de Janeiro: Forense, 1995. p. 253-78.

FISCHER, R.M.B. Adolescência em discurso: mídia e produção de subjetividade. Porto Alegre, 1996. Tese (dout.) Faced/PPGEDU/UFRGS.

A Análise do discurso: para além de palavras e coisas. Educação \& Realidade, v. 20, n. 2, p. 18-37, jul./dez. 1995.

FOUCAULT, M. A Arqueologia do saber. Rio de Janeiro: Forense, 1986.

História da loucura. São Paulo: Perspectiva, 1978.

História da sexualidade /: a vontade de saber. Rio de Janeiro: Graal, 1990.

História da sexualidade // : o uso dos prazeres. Rio de Janeiro. Graal, I990a.

História da sexualidade I/I : o cuidado de si. Rio de Janeiro: Graal, 1985.

Microfísica do poder. Rio de Janeiro: Graal, 1992. 
. L'Ordre du discours. Paris: Gallimard, 1971.

As Palavras e as coisas. Lisboa: Portugália, [s.d.].

O Que é um autor? Lisboa: Vega/Passagens, 1992a.

Vigiar e punir. Petrópolis: Vozes, 1987.

FOUCAULT (org.) Foucault. a critical reader. New York: Basil Blackwell, 1986.

HOY, D. (org.). Foucault. Buenos Aires: Nueva Visión, 1988. p. 7-33: Introdução.

LACLAU, E. A Política e os limites da modernidade. In: HOLLANDA, H. B.(org.). PósModernimo e política. Rio de Janeiro: Rocco, 1991. p. 127-50.

MACHADO, R. Ciência e saber. a trajetória da arqueologia de Michel Foucault. Rio de Janeiro: Graal, 1988.

Foucault e a crítica nietzscheana do humanismo. 1995 [trabalho apresentado no Seminário Foucault: um pensador no coração do presente] Pelotas: UFRGS/NESP. MAINGUENEAU, D. Novas tendências em análise do discurso. Campinas: Pontes; Unicamp, 1993.

MORIN, E. La Méthode, I: la nature de la nature. Paris: Seuil, 1977.

La Méthode, 2: la vie de la vie. Paris: Seuil, 1980.

La Méthode, 3: la connaissance. Paris: Seuil, 1986.

La Méthode, 4: les idées. Paris: Seuil, 1991.

O Problema epistemológico da complexidade. Lisboa: Europa-América, [s.d.], p. 13-34: Problemas de uma epistemologia complexa.

ORLANDI, E. A Linguagem e seu funcionamento: as formas do discurso. Campinas: Pontes; Unicamp, 1987.

PINTO, C. R. J. Com a palavra o senhor Presidente Sarney, ou como entender os meandros da linguagem do poder. São Paulo: Hucitec, 1989.

VEYNE, P. Como se escreve a história: Foucault revoluciona a história. Brasilia: Ed. da UNB, 1982. 